\title{
A criança diante de procedimentos hospitalares: estratégias utilizadas por equipes de saúde - revisão integrativa
}

\author{
The child coping with hospital procedures: strategies developed by \\ health teams - integrative review
}

\section{Nathalia Yumi Takaoka', Daniellle Abdel Massih Pio²}

1Autora para correspondência. Faculdade de Medicina de Marília. Marília, São Paulo, Brasil. ORCID: 0000-0003-4498-6599. nathalia.y.takaoka@gmail.com ${ }^{2}$ Faculdade de Medicina de Marília. Marília, São Paulo, Brasil. ORCID: 0000-0003-0738-4601. danimassihpio@hotmail.com

RESUMO I INTRODUÇÃO: A hospitalização engloba um período de vivências negativas no cotidiano da criança, com valor significativo e repercussões no âmbito social e afetivo. Um dos eventos vividos pela criança durante o período hospitalar vem a ser quando a mesma se depara com a necessidade de ser submetida à intervenções. OBJETIVOS: Identificar estudos que apresentem estratégias utilizadas por equipes de saúde que minimizem o desconforto emocional de crianças hospitalizadas, submetidas a procedimentos invasivos. Método: Trata-se de uma revisão integrativa da literatura, em que foram selecionados 14 artigos científicos, disponíveis, delimitados entre 2002 a 2016. RESULTADOS: Os estudos salientam os benefícios em se preparar as crianças hospitalizadas para procedimentos, minimizando os efeitos negativos da hospitalização. Evidenciam-se produções em maior número das áreas de enfermagem e psicologia, destacando-se a estratégia do Brinquedo Terapêutico Instrucional (BTI). CONCLUSÃO: Fazse necessário, o estabelecimento de programas de preparo para procedimentos de rotina e cirúrgicos nos hospitais pediátricos, além de maior engajamento dos profissionais de saúde em estudos sobre o tema, a fim de que se possa subsidiar as equipes e propiciar às crianças oportunidade de compreensão e elaboração acerca desta experiência.

PALAVRAS-CHAVE: Criança hospitalizada. Humanização da assistência. Equipe de assistência ao paciente.

\begin{abstract}
INTRODUCTION: Hospitalization encompasses a period of negative experiences in child's daily life, with significant value and repercussions in social and affective sphere. One of the events experienced by the child during hospital period comes when he/she is faced with the need to undergo interventions. OBJECTIVES: to identify studies that present strategies used by health teams to minimize the emotional discomfort of hospitalized children undergoing invasive procedures. Method: This is an integrative literature review, in which 14 available scientific articles were selected, delimited from 2002 to 2016. RESULTS: Studies highlight the benefits of preparing hospitalized children for procedures while minimizing the negative effects of hospitalization. It was evidenced more productions were found in areas of nursing and psychology, highlighting the strategy of the Instructional Therapeutic Toy (ITT). CONCLUSION: It is necessary to establish preparation programs for routine and surgical procedures in pediatric hospitals, as well as greater involvement of health professionals in studies on the subject, so that teams can be subsidized and children can be given opportunities to understanding and elaborating about this experience.
\end{abstract}

KEYWORDS: Hospitalized child. Humanization of care. Patient care team. 


\section{Introdução}

A temática do trabalho surge diante da dificuldade dos profissionais inseridos em hospitais, que se relacionam com o público infantil, em possibilitarem que o momento de internação seja envolto com o que é necessário para uma hospitalização adequada e dentro dos moldes que se discute na saúde pública: a humanização.

Humanizar, de acordo com a Cartilha da Política Nacional de Humanização (Ministério da Saúde, 2013), significa pensar nas diferenças e individualidade de cada ser, desde a gestão, até o serviço assistencial. Organizar o trabalho, de modo coletivo e compartilhado, disponibilizando acolhimento, de maneira a construir o cuidado.

Atualmente, tratando-se da participação de crianças em pesquisas pediátricas e biomédicas, têm se levado em consideração o consentimento, envolvimento e disposição das mesmas mediante o processo, para além dos pais. O que evidencia a valorização da criança também como sujeito na pós modernidade, uma vez que ela se apropria de participar das pesquisas, deverá ela também participar como protagonista de seu tratamento (Lobato et al. 2016).

A hospitalização costuma ser um evento caracterizado por angústia do paciente, relativa ao seu quadro geral de saúde, o qual acentua-se a ansiedade, o medo e expectativas, as quais influenciarão diretamente em como vivenciará este novo contexto. Nas crianças, muitas vezes, a internação é vista de forma ainda mais ameaçadora, em que suas fantasias podem assimilar a doença como castigo, culpabilização, sentimentos de abandono, dentre outros, vivenciados sob ótica negativa. Isto pode ser amenizado na presença de uma assistência familiar de apoio, com figuras que facilitem sensações de segurança, proteção e acompanhamento devido (Dantas, Nóbrega, Pimenta, \& Collet, 2016).

Pensando a respeito do cuidado humanizado dentro das instituições pediátricas, faz-se necessária a promoção de uma assistência que minimize os desconfortos e o impacto da internação hospitalar para o público, contribuindo para uma adaptação acolhedora. Um estudo de Torquato et al. ( 2013), sobre a percepção dos acompanhantes em relação a assistência humanizada à criança, apontou que um dos caminhos para a construção da humanização se estabelece na relação dialógica entre profissional, paciente e acompanhante; no respeito ofertado e na valorização da pessoa humana. Discute-se que, quando o profissional compreende as dificuldades e os enfrentamentos que a família tem que realizar, viabiliza-se uma prática que se consolida de maneira empática, e favorável para a recuperação da saúde. No mesmo estudo, os acompanhantes, também sinalizam espaços recreativos e a oferta de materiais lúdicos como possibilidade de redução de ansiedade e estresse dentro do ambiente hospitalar.

Com o avanço e valorização da busca pelo conhecimento, muitas das pesquisas encontradas nas áreas da medicina, pedagogia, psicologia, atualmente nos permitem viabilizar que a criança é um ser que se constrói a partir de arranjos familiares, que a moldam socialmente. Vivendo em um mundo interno de características distintas da fase adulta, elas sentem e pensam o mundo de maneiras diferentes das do adulto, utilizam da interação com o meio para a compreensão da realidade, e se apropriam de linguagens diferentes para se expressar, sendo uma delas, o brincar (Oliveira, 2008).

Assim, pensar sobre a infância e suas distinções em relação à fase adulta, faz-nos pensar em diferenças relacionadas à apropriação de linguagem e pensamento que vem de um movimento histórico mais recente. São estes movimentos que individualizam e nos mostram que a criança é um ser com necessidades e mundo interno diferente das do adulto, portanto, ela apresenta obrigatoriedade de um conjunto de práticas e intervenções distintas.

De acordo com Brasil (1998), o conceito de criança, vem se modificando historicamente e culturalmente, e mostra-se diferente da visão arcaica que outrora se discutira. Desta forma, garantir a expressão de sentimentos vividos pela criança e poder oportunizar que ela viva sua condição de criança e, não apenas de paciente dentro das instituições hospitalares é essencial.

A criança hospitalizada além de estar sob a necessidade de cuidados que imperam a questão física, fica diante de uma realidade onde precisa vivenciar a distância familiar, e das pessoas significativas a ela, readequar-se a uma rotina com pessoas desconhecidas, sendo ela, privada de sua vida cotidiana. Desta maneira, é importante a possibilidade de um meio que traga conforto e acolhimento, permitindo que estes ressignifiquem o período vivenciado (Kovács, 2008). 
Durante a necessidade de hospitalização da criança, há necessidade de se criar um ambiente que proporcione condições para que ela se desenvolva, na mesma medida em que faz-se necessário a promoção de um espaço acolhedor, que oportunize chances de recuperação da saúde, permitindo acesso às informações relativas ao momento vivenciado de acordo com seu desenvolvimento cognitivo, apoio seguro e favorecimento de expressar-se (Castro et al. 2010).

Tendo em vista o evento de impacto emocional, que é a hospitalização, com destaque para as intervenções hospitalares que produzem reações comportamentais negativas entre as crianças internadas, atualmente, estudos que enfatizam a humanização no contexto hospitalar, vem conceituando a potencialidade de se preparar a criança diante de procedimentos, contribuindo para a redução do sofrimento durante este período.

Como meio de comunicação entre profissionais da saúde e o paciente pediátrico, pesquisas direcionadas ao olhar do paciente infantil durante a necessidade de internação, apontam a importância do brincar e de recursos lúdicos para a criança, favorecendo etapas do desenvolvimento, possibilitando a externalização de sentimentos, e a compreensão das necessidades de intervenções.

O brincar se consolida por ser uma ação espontânea e natural do indivíduo, que potencializa benefícios à saúde mental, possibilitando um agrupamento de ações, onde a criança se manifesta, representa aquilo que vivencia, permite-se envolver e fantasiar uma realidade de maneira consciente (Gimenes, 2008).

Jensen, Santos e Favero (2010), salientam que utilizar o brinquedo em experiências consideradas hostis pela criança, contribui para a elaboração dos acontecimentos e amenização da ansiedade. Assim, diante da rotina hospitalar, o uso, por exemplo, do boneco terapêutico pela equipe de enfermagem possibilita ao paciente dramatizar as intervenções pelas quais passarão, de modo que favoreça seu conhecimento e facilite o manejo de comportamentos resistentes.

Mitre e Gomes (2004) abordam o brincar dentro das instituições hospitalares como uma ação estratégia terapêutica que promove além de progresso no desenvolvimento infantil, melhora na capacidade de enfrentamento deste público.
Um espaço que promove ações de brincadeiras, direciona a criança para expressão de sua individualidade, essencial para restabelecimento da saúde. O lúdico possibilita a reestruturação física e representa o simbólico, permitindo a criança projetar, organizar, aprender e elaborar as situações vivenciadas, externalizando sentimentos, defesas e conteúdos que se aproximam de recursos saudáveis, permitindo que ela possa organizar-se em seus aspectos físicos e psicológicos (Oliveira, 2008).

O estudo de Depianti, Melo, \& Ribeiro (2018), que enfatiza a importância de se proporcionar o brincar dentro das instituições hospitalares infantis, verificou que através do lúdico, pacientes de um setor de oncologia, descreveram o hospital como sendo um ambiente envolto por sofrimento, que se caracteriza por um espaço limitador. Demonstraram que significam os profissionais de saúde como aqueles que realizam as intervenções que geram sensações de angústia e desconforto, sendo lembrados os procedimentos.

Os autores Faleiros, Sadala, \& Rocha (2002), sinalizam a importância de se vincular à criança hospitalizada, promovendo um ambiente envolto por empatia e atitudes que favoreçam a confiança na equipe, sendo uma das formas, a comunicação.

Dentro do período de hospitalização, um estudo de Eckenhoff (1953) apud Crepaldi e Broering (2008), enfatiza que a anestesia e as cirurgias proporcionam sofrimento às crianças, podendo acarretar em perturbação psicológica até mesmo posterior a saída do hospital. Seus dados relacionam a faixa etária de seis meses a seis anos, como sendo as mais prejudicadas, visto a dificuldade maior de elaboração de algumas vivências.

Com relação ao desenvolvimento de estratégias para amenizar o impacto do período de hospitalização, Crepaldi e Broering (2011) datam das décadas de 1960 e 1970, estudos que começam a destacar os benefícios do preparo dos pacientes pediátricos para procedimentos invasivos e cirúrgicos, trazendo a relevância também da importância dos pais durante a internação das crianças, favorecendo uma melhor adaptação durante e após a internação.

Para Garcés e Assef (2004), a preparação psicológica beneficia a apropriação do paciente ao procedimento, favorecendo a compreensão e tomada de decisões. Segundo os autores, a estratégia de preparo, com 
base nos hospitais que já implantaram programas no qual se oferece apoio, e em que se prepara o paciente para intervenções, há uma receptividade maior às abordagens e procedimentos, além da redução dos níveis de ansiedade, não apresentando sintomas negativos causados pela internação, mesmo após a alta. A técnica de preparo para intervenções, também não exclui os pais ou acompanhantes, que se sentem mais confortáveis frente aos procedimentos realizados.

Oferecer este cuidado aos pais também se mostra importante, pois desta forma, eles adquirem maior segurança sobre o andamento da internação das crianças, as intervenções que serão realizadas, podendo contribuir para que a criança se apresente menos ansiosa e confortável diante do período de confinamento hospitalar (Broering \& Crepaldi, 2008).

Assim, diante do exposto acerca da importância do investimento e da consolidação dos projetos de humanização que visam preparar o paciente, pretende-se identificar estudos que apresentem estratégias utilizadas por equipes de saúde que minimizem o desconforto emocional de crianças hospitalizadas, submetidas a procedimentos invasivos.

Delimita-se como problema de pesquisa, a dificuldade dos profissionais atuantes em unidades pediátricas de se considerar a criança como participante ativo do processo saúde-doença, e enxergá-la como ser que vivencia seu tratamento, manifestando-se a partir de reações comportamentais.

\section{Método}

Trata-se de um estudo de revisão integrativa de literatura, que permite o levantamento de pesquisas em relação à temática abordada, resultando na sistematização de conteúdos significativos sobre o objetivo a ser explorado (Souza, Silva, \& Carvalho, 2010).

Teve-se como objetivo responder à seguinte questão norteadora: Quais são as estratégias utilizadas por profissionais, que atuam em hospitais infantis, para acolher e preparar a criança para procedimentos invasivos ou cirurgias?

A busca dos artigos foi realizada na base de dados LILACS e na Scientific Electronic Library Online (SciELO), utilizando os seguintes descritores presentes na Biblioteca Virtual em Saúde (BVS): criança hospitalizada, humanização da assistência, equipe de assistência ao paciente, ligados por meio do uso do operador booleano AND separados no idioma português.

Como condições para as buscas, foram utilizados os seguintes critérios de inclusão: artigos disponíveis na íntegra, online, gratuitamente publicados a partir dos anos 2002, com a justificativa do período de inclusão extenso pela carência de pesquisas disponíveis. $\mathrm{Na}$ seleção dos estudos priorizou-se aqueles que abordassem os efeitos do preparo para procedimentos, com foco nos benefícios de um preparo hospitalar. Optou-se por incluir no trabalho artigos direcionados ao público hospitalar infantil, excluindo estudos onde o objetivo principal resultasse no público adulto, abarcando apenas um artigo que envolve este público, mas ao qual o estudo contempla as duas populações.

Os critérios de exclusão adotados foram: teses, textos incompletos, livros, resumos, cartas ao editor, resenhas, e artigos que não contemplassem a questão norteadora nas respectivas bases de dados, LILACS e SCIELO.

Instituiu-se para a coleta de dados um instrumento que extraiu dos artigos selecionados os seguintes dados: título do artigo; autor/ano de publicação; objetivos; metodologia; principais achados, com foco no encontro de estratégias utilizadas pelos profissionais, na redução dos impactos gerados pelos procedimentos hospitalares.

Para realização do trabalho, foram feitas leituras criteriosas dos artigos. Obtiveram-se dificuldades em encontrar estudos recentes, o que mobilizou a sintetizar artigos de até 17 anos atrás. Levantou-se um total de 14 artigos que se encaixavam na temática proposta.

\section{Resultados e discussão}

Foi elaborado um quadro (Quadro 1) com os dados dos 14 artigos encontrados (indicados de $\mathrm{A}$ à $\mathrm{O}$ ) e selecionados para visualização e compreensão dos resultados. A descrição apresenta os artigos selecionados, incluindo metodologia, e os principais achados, abrangendo o ponto de vista dos autores, suas recomendações e conclusões. 


\begin{tabular}{|c|c|c|c|c|c|}
\hline 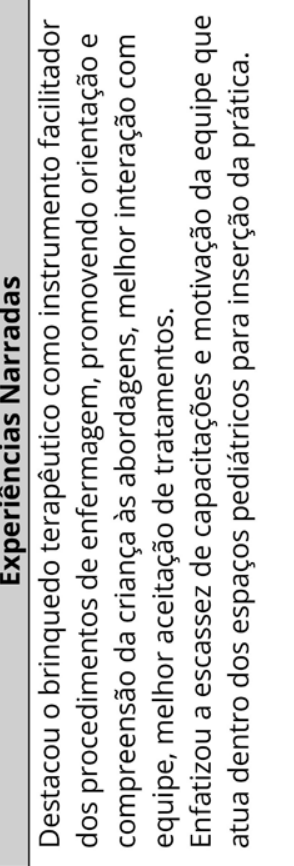 & 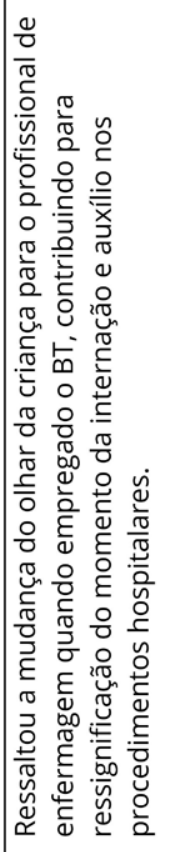 & 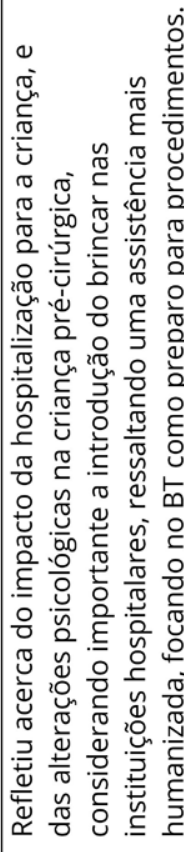 & 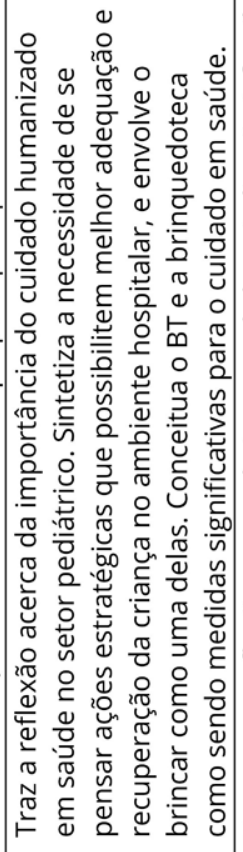 & 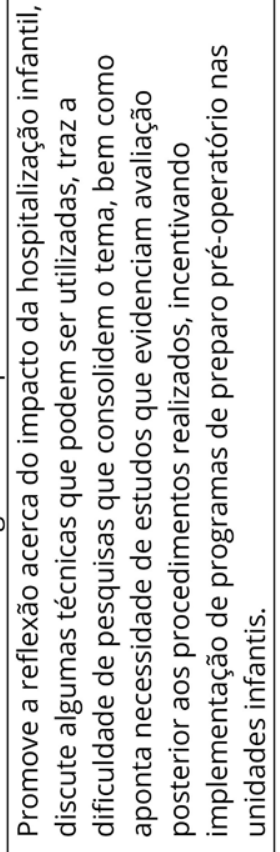 & 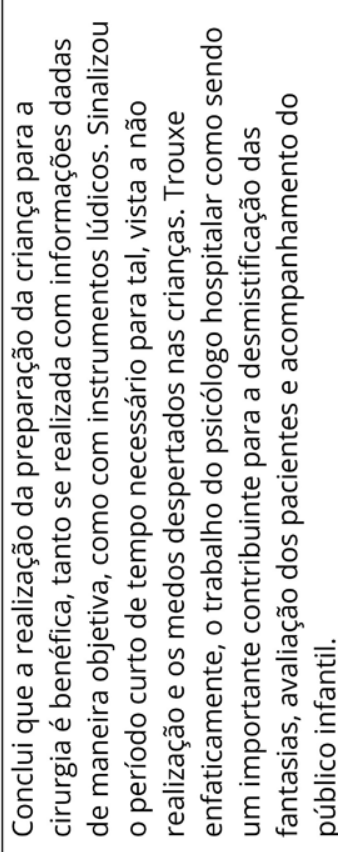 \\
\hline 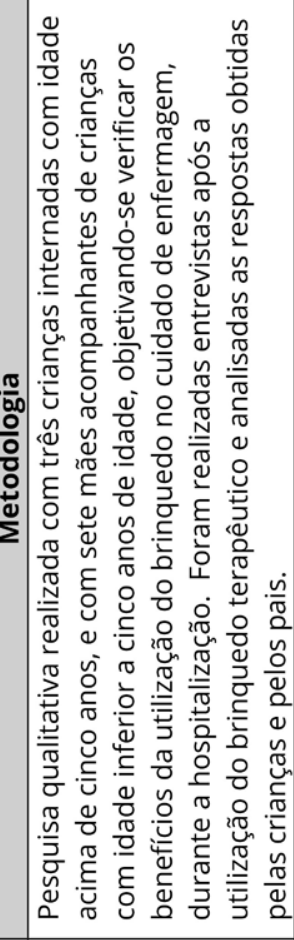 & 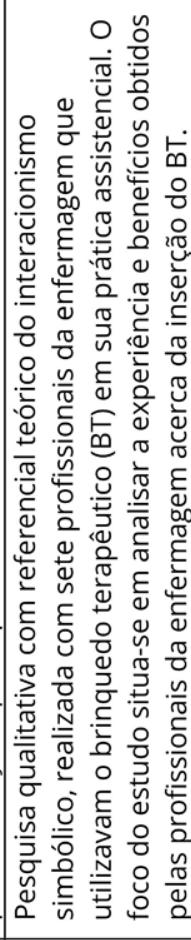 & 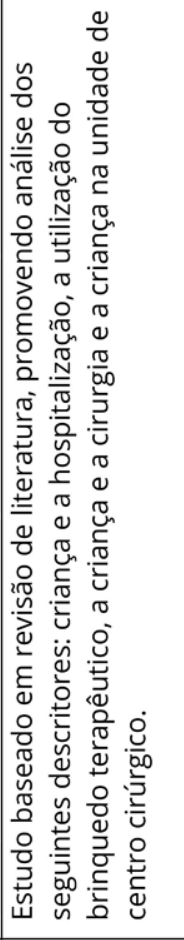 & 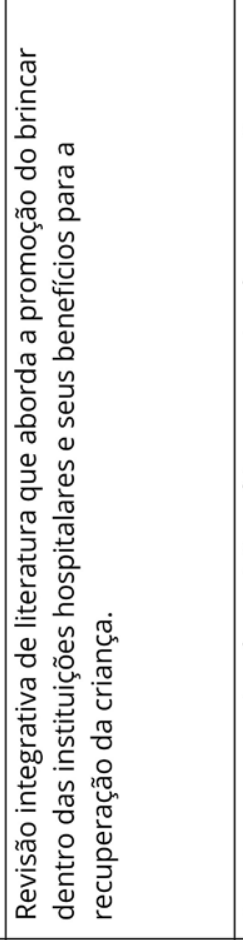 & 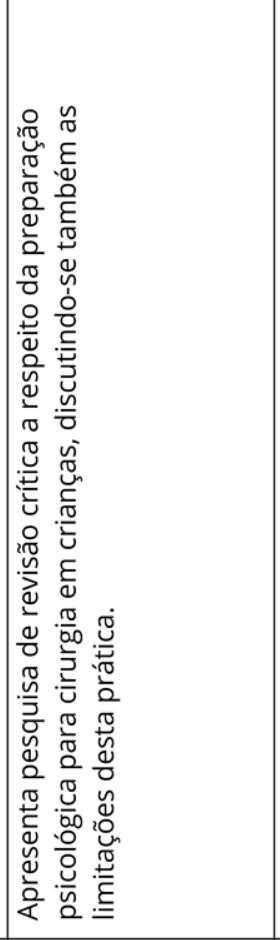 & 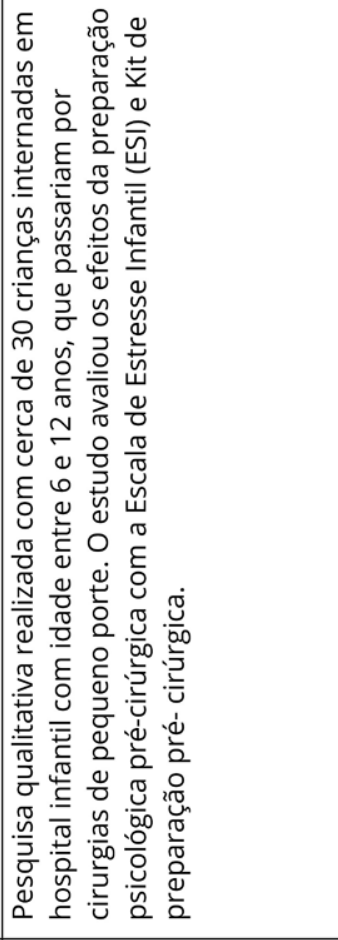 \\
\hline 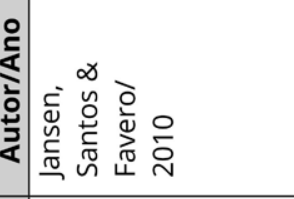 & 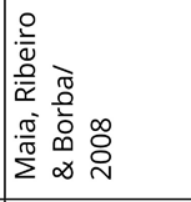 & 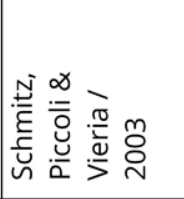 & 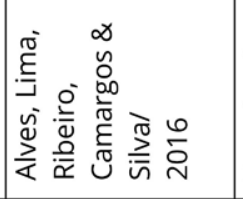 & 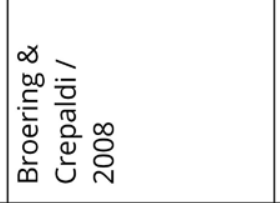 & 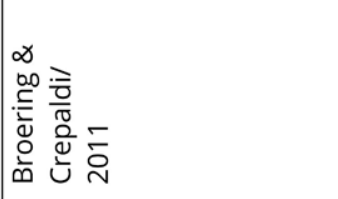 \\
\hline 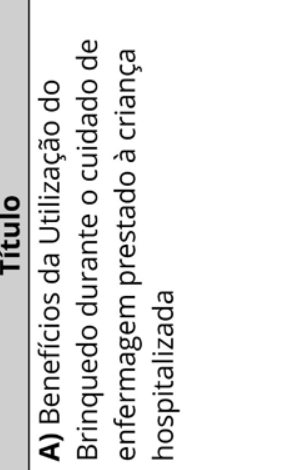 & 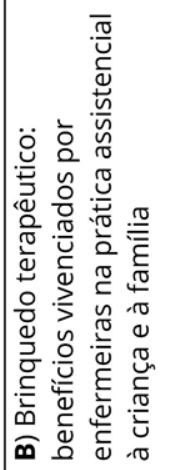 & 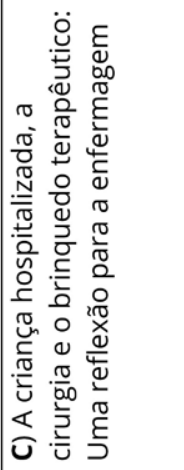 & 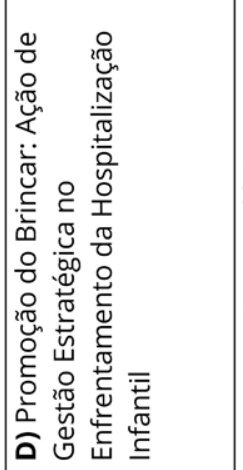 & 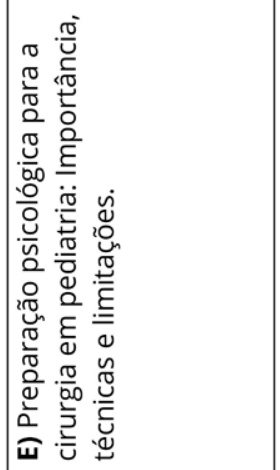 & 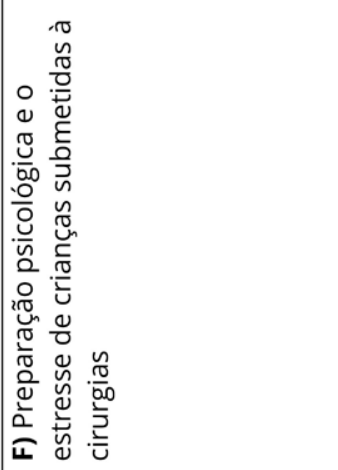 \\
\hline
\end{tabular}




\begin{tabular}{|c|c|c|c|c|c|c|}
\hline 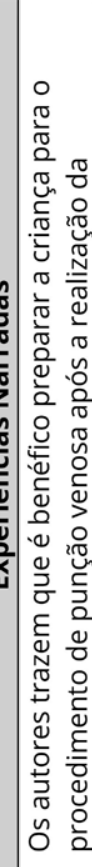 & 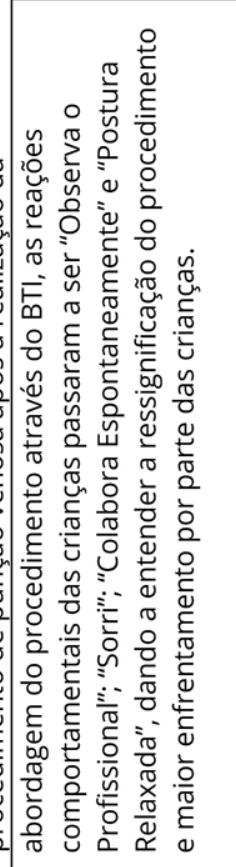 & 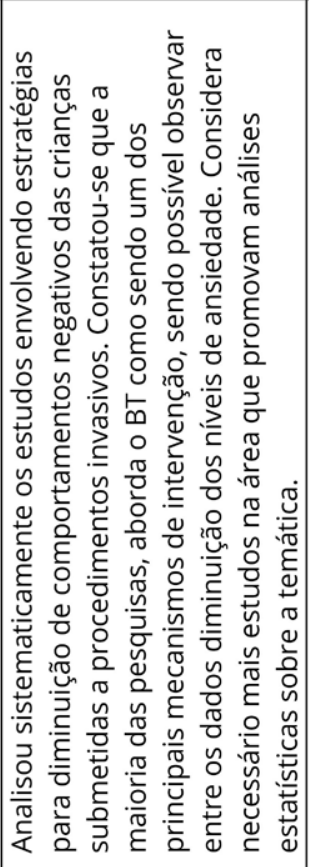 & 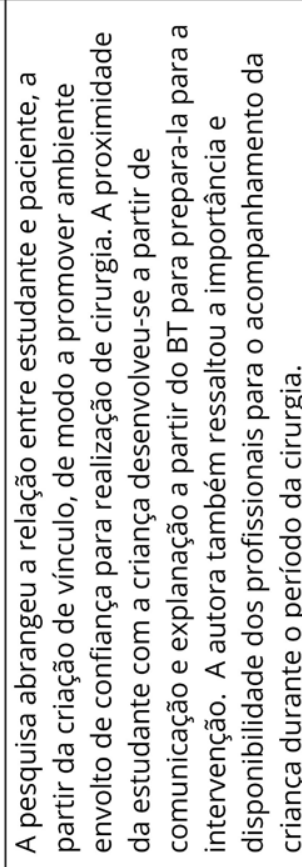 & 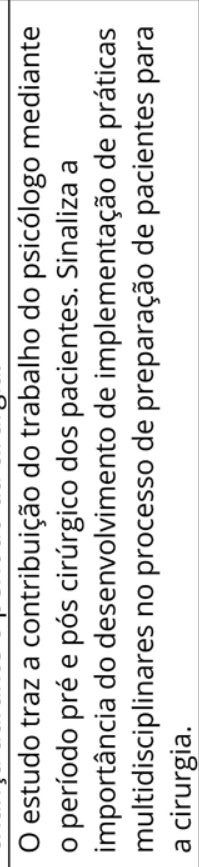 & 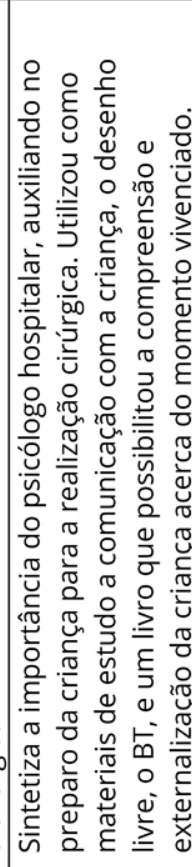 & 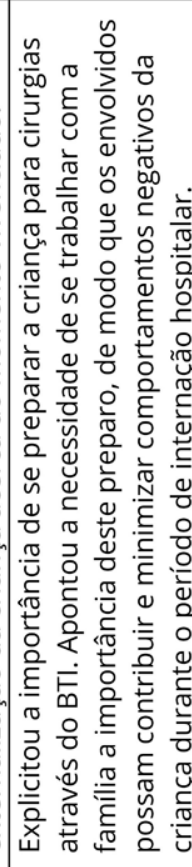 \\
\hline 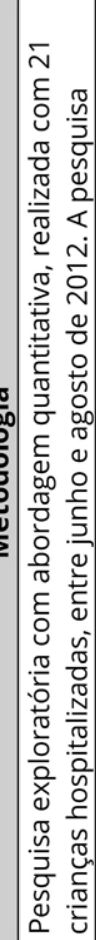 & 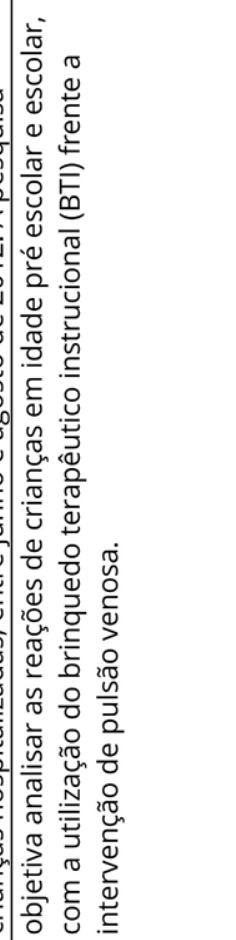 & 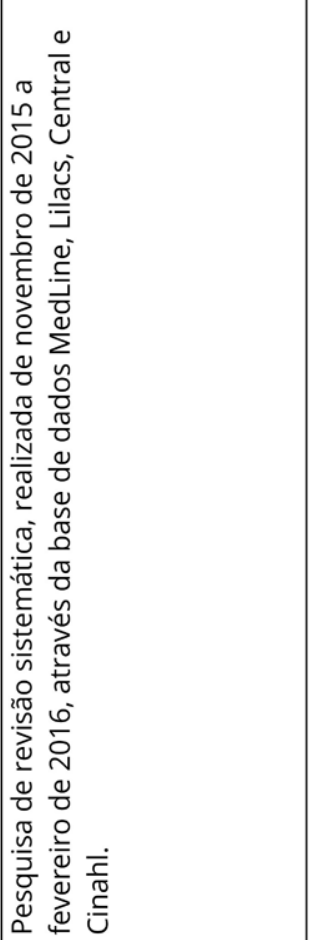 & 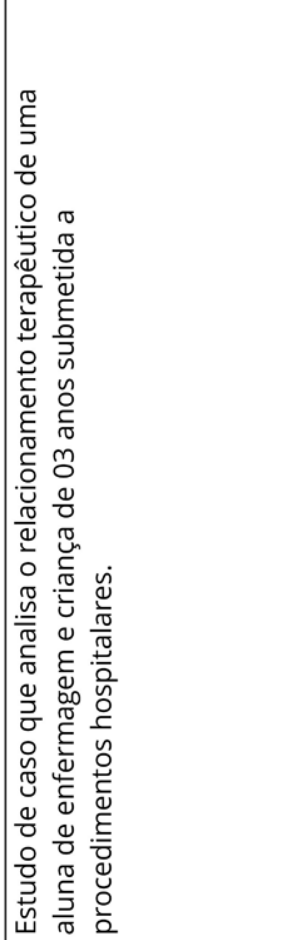 & 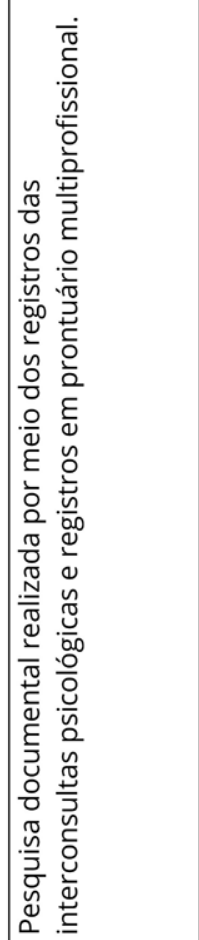 & 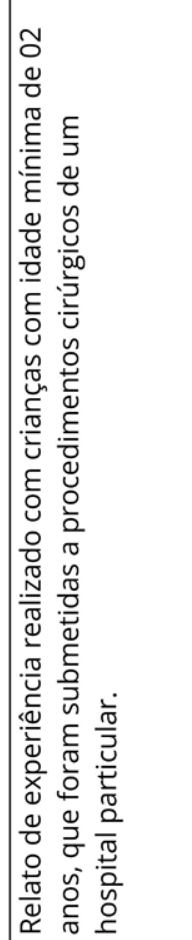 & 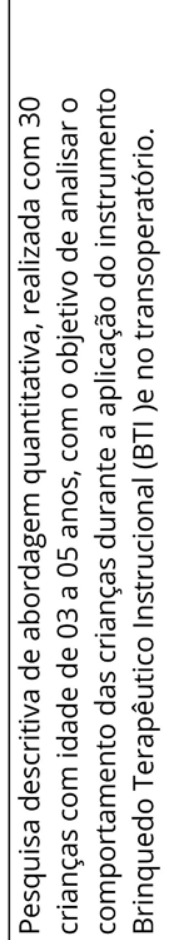 \\
\hline 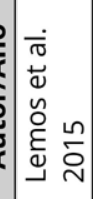 & 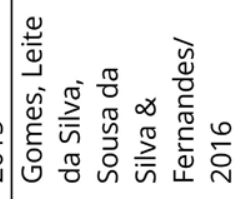 & 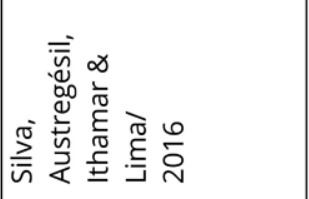 & 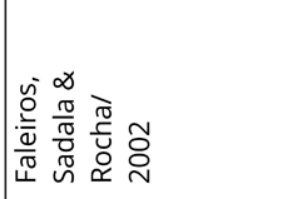 & 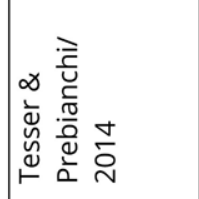 & 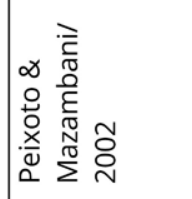 & 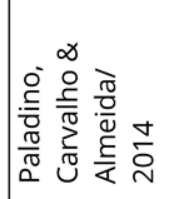 \\
\hline 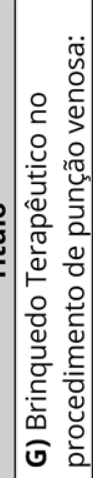 & 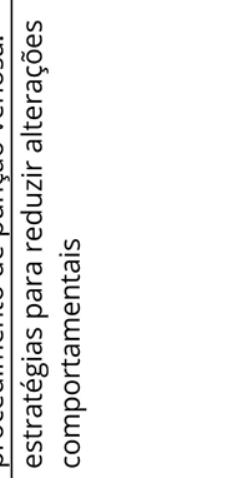 & 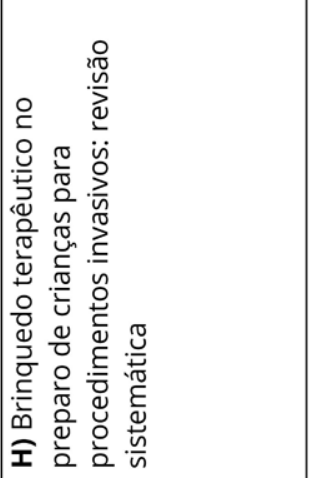 & 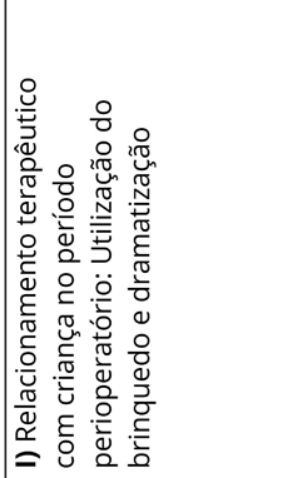 & 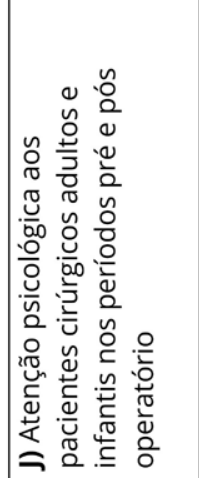 & 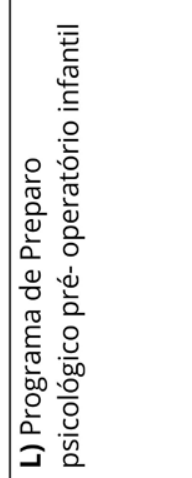 & 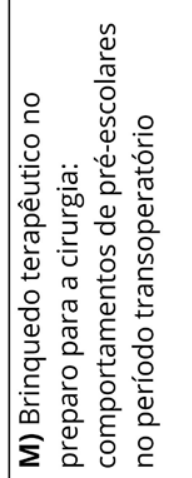 \\
\hline
\end{tabular}




\begin{tabular}{|c|c|c|}
\hline & 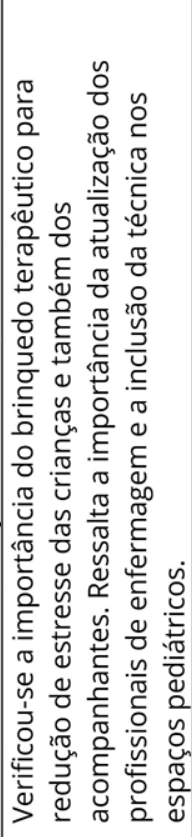 & 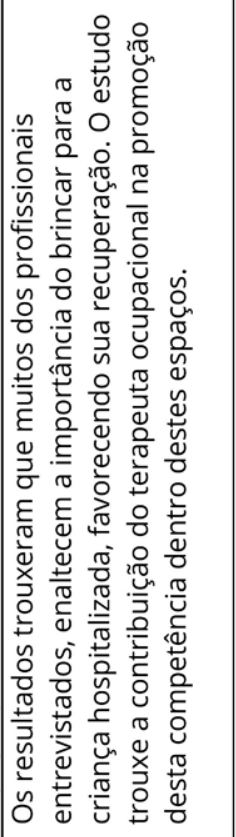 \\
\hline & 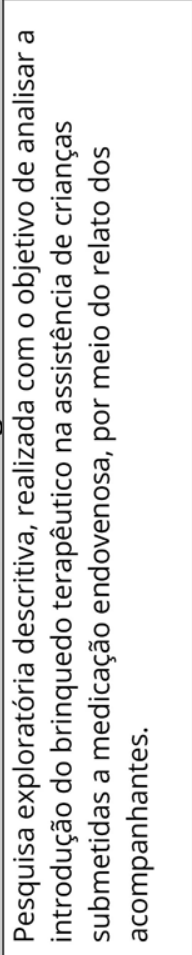 & 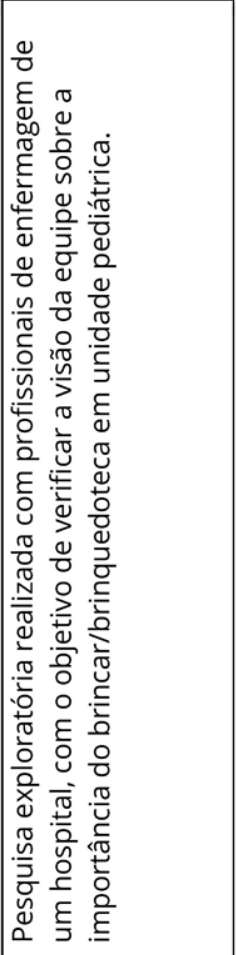 \\
\hline & 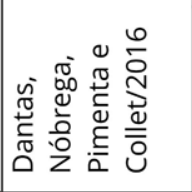 & 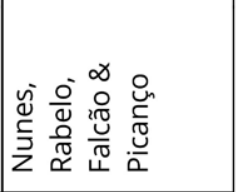 \\
\hline & 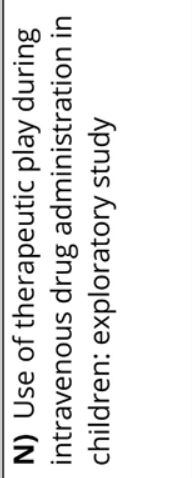 & 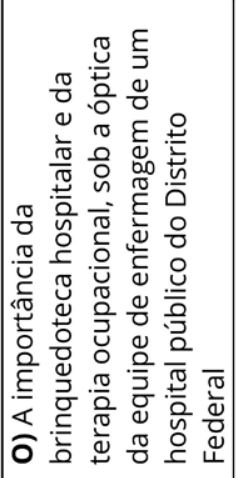 \\
\hline
\end{tabular}


A partir dos estudos procurou-se fazer uma síntese de aspectos relevantes que contribuam para a viabilidade do desenvolvimento de estratégias que possam humanizar o contexto pediátrico:

Em relação às estratégias já utilizadas no setor hospitalar encontraram-se nos artigos expostos no quadro:

- Brinquedo Terapêutico Instrucional (BTI): 10 estudos

- Brinquedoteca: 2 estudos;

- Programas de preparo pré-operatório: 4 estudos;

- Desenho livre: 1 estudo;

- Livro: 1 estudo.

Os estudos de BTI são realizados em hospitais, permitindo que a criança tenha um objeto que possa ser referência, para oferecer conforto em situações consideradas atípicas ao seu dia a dia, envoltas por estresse, ou para ser utilizado para que ela conheça os procedimentos no qual passará durante o período de internação. Por meio do BTI, a criança recebe informação através do profissional de saúde de como será realizada a intervenção a qual será submetida, quando o profissional utiliza dos próprios materiais hospitalares que serão usados no paciente, explicando sua funcionalidade, e a criança repete as instruções ofertadas no brinquedo, possibilitando assimilar a intervenção. Ainda, o brinquedo terapêutico, geralmente um boneco, pode acompanhar a criança por todo período de internação, representando-se como objeto que simbolize segurança, permitindo que ao brincar, se dramatize tudo aquilo que encontra dificuldade de verbalizar (Jansen, Santos, \& Favero, 2010).

Uma análise relacionada ao brinquedo terapêutico na administração de medicação endovenosa com crianças, observou que, na necessidade de uma intervenção como esta, as crianças apresentam-se bastante ansiosas, agitadas, e apresentando reações de choro. Quando utilizado o brinquedo terapêutico, concretiza-se uma maior aceitação do procedimento pelas crianças, entendimento de sua necessidade para recuperação de saúde, e até mesmo, diversão dentro do ambiente hospitalar. Os mesmos benefícios são identificados pelos acompanhantes que solicitaram a implementação deste recurso durante a hospitalização das crianças, como forma de amenização de angústia, também de si próprias, que participam do confinamento hospitalar (Dantas, Nóbrega, Pimenta, \& Collet, 2016).
Em meados de 2005, surge a brinquedoteca hospitalar, como uma obrigatoriedade dentro das instituições pediátricas, fundamentando a liberdade de expressão da criança em situações de internação e como meio de manutenção da saúde mental. A partir de um lugar estruturado, com livros de diversos conteúdos, as crianças entram em contato com o lúdico, e permitem-se caminhar por lugares distintos, que dão funcionalidade ao imaginário, oferecendo possibilidades para que a criança entre em contato com entretenimento e encontre recursos que promovam a recuperação da saúde (Alves, Lima, Ribeiro, Camargos, \& Silva, 2016).

Um estudo que valoriza a brinquedoteca hospitalar e a função de terapeuta ocupacional, destaca que oportunizar esta ferramenta dentro de um ambiente envolto por adoecimento, amplia as relações do paciente e profissional, além de possibilitar acolhimento, diálogo e redução de estresse (Nunes, Rabelo, Falcão, \& Picanço, 2013).

Peixoto e Mazambani (2008), trazem técnicas de desenho livre, como ofertas de uma folha em branco para que a criança desenhe aquilo que sabe sobre o ambiente hospitalar, e a utilização de livros de histórias, podendo ser específicas, como a "Operação de Lili" (Alves, 2016). Segundo os autores, por meio destes recursos faz-se possível o diálogo e explicação das necessidades das intervenções, também sendo possível conhecer as expectativas e fantasias que elas trazem sobre o processo da hospitalização.

Acerca do benefício do preparo para intervenções, os estudos potencializaram:

- Diminuição do impacto da hospitalização: 11 estudos;

- Facilitador dos procedimentos de enfermagem: 5 estudos;

- Compreensão da criança acerca do procedimento: 2 estudos;

- Melhora do vínculo com a equipe: 5 estudos;

- Instrui a família e os apóia acerca das reações comportamentais da criança: 1 estudo.

A criança é considerada um ser que interage diretamente com o meio, um ator social que atribui interpretação a cada momento experimentado a partir de suas próprias elaborações. Através do brinquedo ou material lúdico, passa a ter voz, e comunica aquilo que vivencia, passando ao desenvolvimento 
e constituição de uma relação com o profissional de saúde, permitindo assim, sua valorização e ressignificação de personagem principal do cenário, desmistificando sua participação limitada no processo saúde, doença, hospitalização.

As potencialidades de se preparar as crianças para as intervenções favorecem que a criança sintam-se mais à vontade dentro destes ambientes, e continue a vivenciar o período da maneira como se é esperado: ser criança.

O brinquedo e o lúdico fornecem segurança e funcionam como tranquilizantes, para que estas possam se adaptar ao momento (Jansen, Santos, \& Favero, 2010). O reconhecimento do brincar como importante dentro das instituições pediátricas, se apresenta como uma forma de se chegar ao cuidado integral e complexo à criança e sua família, proporcionando aos mesmos fortalecimento para os enfrentamentos necessários durante o período de confinamento hospitalar (Alves, Lima, Ribeiro, Camargos, \& Silva, 2016).

O estudo de Broering e Crepaldi (2011), vem sinalizar as intervenções necessárias ao cuidado, acerca da preparação de crianças para cirurgias, salientando que a privação de informações no contexto hospitalar, promove medo, ansiedade, estresse, angústia, explicitando a importância de se preparar o público infantil para tais procedimentos. Apresentam os resultados descritos como reações negativas às cirurgias e alterações comportamentais importantes, posteriores ao período de internação. Destaca os efeitos da preparação psicológica pré-cirúrgica com a Escala de Estresse Infantil (ESI) e Kit de preparação pré-cirúrgica.

Broering e Crepaldi (2008), discutem que apesar da temática em relação às técnicas que preparam a criança para procedimentos seja evidenciada em alguns estudos, ainda se fazem necessárias pesquisas que se contemplem mais abrangentes e tragam os benefícios dos preparos em resultados, enaltecendo a eficácia, por exemplo, da criação de programas instituídos em hospitais infantis. A dificuldade de realização destes estudos, segundo as autoras, deve-se à complexidade de se avaliar o resultado obtido no momento pós-aplicação da intervenção, e também posterior ao procedimento hospitalar necessário, vista que em alguns cuidados, especialmente o cirúrgico, a criança encontra-se sedada ou ainda sob seu efeito, o que dificulta sua reavaliação.
Os resultados obtidos neste estudo mostram a existência de pesquisas que objetivam destacar a importância da aplicação da Política Nacional de Humanização nos espaços hospitalares infantis. No entanto, foi difícil a localização de pesquisas que abordassem o que vêm sendo praticado em relação ao cuidado humanizado para a criança mediante as intervenções hospitalares, e quando abordados, foi observável que, as contribuições geralmente vêm de análises que não são dos últimos cinco anos, notando-se também dificuldade para encontrar títulos que evidenciassem recursos lúdicos para enaltecer a participação e protagonização da criança nestes espaços.

\section{Considerações finais}

É imprescindível que, ao adentrar no hospital, seja realizada uma avaliação integral da criança, que possibilite a compreensão de seu estado de saúde/saúde mental, tendo em vista que a hospitalização sempre será um marco de estresse para a mesma.

Fica claro, neste estudo, a importância do brincar para a criança em seu desenvolvimento, o que não deve ser restringido diante da necessidade dela pertencer a um espaço hospitalar. Neste trabalho, os recursos lúdicos têm o foco de viabilizar um ambiente acolhedor e humanizado para o paciente infantil, de modo que possam contribuir para que a criança obtenha informação a respeito do que será feito com ela, participar deste processo, permitindo sua melhor adaptação e elaboração dos processos saúde-doença.

Pode-se entender por meio do trabalho, que existem diferentes maneiras de humanizar o processo de intervenções hospitalares para a criança, sendo que alguns destes recursos sequer prescindem de soluções mais elaboradas, como por exemplo, possibilitar a criança conhecer os procedimentos através de falas sensíveis ao seu momento e desenvolvimento cognitivo, ou através de realização de um desenho que permita a expressão fidedigna de seus receios e fantasias.

No estudo realizado, observou-se que as categorias que desenvolveram mais pesquisas em relação as estratégias de cuidado com a criança diante de procedimentos, foram Enfermagem e Psicologia, sendo um estudo da Terapia Ocupacional. Desta forma, valoriza-se que todos os profissionais de saúde possam se debruçar acerca de pesquisas sobre o tema, 
tornando-se habilitadas e engajadas ao desenvolvimento de estratégias que viabilizem a amenização das repercussões negativas na criança, especialmente diante das intervenções, trazendo-Ihes a oportunidade de um ambiente harmonioso e acolhedor, tornando possível a redução dos impactos da internação.

Talvez, mediante ao grande número de demandas por todos os profissionais que se inserem na equipe de saúde, podemos pensar que, tratando-se de pacientes infantis, possivelmente estratégias estejam sendo realizadas relacionados ao cuidado, no entanto, há pouca divulgação destas ações, considerando as publicações. A divulgação das estratégias de redução de sofrimento durante intervenções hospitalares resultaria em consideráveis contribuições aos colegas de profissão e também aos pacientes beneficiários da implementação de novas técnicas, enriquecendo o campo das pesquisas.

Foi possível perceber que proporcionar às crianças um ambiente acolhedor, envolto por atenção, comunicação e possibilidade de expressão dos sentimentos diante dos procedimentos a serem realizados, traz ao paciente e ao acompanhante sensação de amparo, tornando possível uma internação menos traumática.

Refletimos que, muitas vezes dentro das instituições percebe-se que os profissionais acabam por não incluir o paciente no cuidado, especialmente levando-se em consideração as crianças, sendo visível a falta de comunicação ou habilidade de se relacionar com este público. Isso reflete em reações desfavoráveis e não colaborativas a todo o processo de recuperação.

Pela análise das pesquisas, percebe-se que a maioria dos estudos utilizou como instrumento para proximidade com a criança no contexto hospitalar o BTI, possibilitando aos pacientes a construção e representação das intervenções em que são submetidos. Além disso, observa-se que, independente dos materiais lúdicos, a possibilidade de comunicação e expressão, para que as crianças coloquem suas dúvidas, foi considerada medida favorável.

Analisando as propostas e as estratégias utilizadas nas pesquisas, e pensando acerca da promoção de saúde e humanização aos pacientes pediátricos, identifica-se a importância das instituições refletirem criticamente sobre como se encontra a atuação profissional dentro dos espaços de cuidado infantil, bem como sobre as dificuldades encontradas para atuação, e que seja reconhecida a necessidade de constante reformulação do cuidado, exigindo maior preparo dos profissionais, inovações, capacitações ou elaborações de meios que possam resultar em saúde em sua integralidade.

Sugere-se mais estudos que abordem a temática, bem como a implementação de programas que visem o preparo da criança para procedimentos hospitalares, trazendo o foco para os objetivos alcançados, tornando possível a humanização do cuidado nos espaços pediátricos, e aumentando o acervo de pesquisas nessa temática.

\section{Contribuições das autoras}

Takaoka, N. Y. participou da elaboração do projeto, busca e análise dos dados e redação do artigo. Pio, D. A. M. orientou todas as etapas do trabalho e participou da redação e revisão do artigo.

\section{Conflitos de interesses}

Nenhum conflito financeiro, legal ou político envolvendo terceiros (governo, empresas e fundações privadas, etc.) foi declarado para nenhum aspecto do trabalho submetido (incluindo mas não limitando-se a subvenções e financiamentos, participação em conselho consultivo, desenho de estudo, preparação de manuscrito, análise estatística, etc.).

\section{Referências}

Alves, J. F., Lima, M. D. O., Ribeiro, R. M., Camargos, M. C. S., \& Silva, K. R. (2016). Promoção do Brincar: Ação de Gestão Estratégica no Enfrentamento da Hospitalização Infantil. Gerais: Revista de Saúde Pública do SUS/MG, 4(1), 89100. Recuperado de http://docs.bvsalud.org/biblioref/ coleciona-sus/2016/35351/35351-1119.pdf

Araújo, S. V. N., \& Henrique, S. S. (2012). Visita de enfermagem pré-operatória com finalidade educativa para o procedimento cirúrgico. Comunicação em Ciências da Saúde, 23(4), 297-304. Recuperado de http://bvsms.saude. gov.br/bvs/artigos/visita_enfermagem_preoperatoria.pdf

Broering, C. V., \& Crepaldi, M. A. (2008). Preparação psicológica para a cirurgia em pediatria: Importância, técnicas e limitações. Paideia, 18(39), 61-72. Recuperado de http:// www.scielo.br/pdf/paideia/v18n39/v18n39a07.pdf. doi: 10.1590/S0103-863X2008000100007 
Broering, C. V., \& Crepaldi, M. A. (2011). Preparação psicológica e o estresse de crianças submetidas a cirurgias. Psicologia em Estudo, 16(1), 15-23. Recuperado de http://www.scielo. br/pdf/pe/v16n1/a03v16n1.pdf. doi: 10.1590/S141373722011000100003

Castro, D. P., Andrade, C. U. B., Luiz, E., Mendes, M., Barbosa, D., \& Santos, L. H. G. (2010). Brincar como instrumento terapêutico. Pediatria, 32(4), 264-54. Recuperado de https://www.researchgate.net/profile/Luiz_Santos31/ publication/280947178_Brincar_como_instrumento_ terapeutico/links/55ce1eac08ae118c85bdfac6.pdf

Dantas, F. A., Nóbrega, V. M., Pimenta, E. A. G., \& Collet, N. (2016). Use of therapeutic play during intravenous drug administration in children: exploratory study. Online Brazilian Journal of Nursing, 15(3), 454-465. Recuperado de http://objnursing.uff.br/index.php/nursing/article/ view/5581/pdf_1

Depianti, J. R. B., Melo, L. L., \& Ribeiro, C. A. (2018). Brincando para continuar a ser criança e libertar-se do confinamento da hospitalização em precaução. Escola Anna Nery, 22(2), e20170313. Recuperado de http://www.scielo.br/pdf/ ean/v22n2/pt_1414-8145-ean-22-02-e20170313.pdf. doi: 10.1590/2177-9465-EAN-2017-0313

Faleiros, F., Sadala, M. L. A., \& Rocha, E. M. (2002). Relacionamento Terapêutico Com Criança no Período Perioperatório: Utilização do Brinquedo e da Dramatização. Revista da Escola de Enfermagem da USP, 36(1), 58-65. Recuperado de http://www.scielo.br/pdf/reeusp/v36n1/v36n1a08.pdf. doi: 10.1590/S0080-62342002000100009

Garcés, C. B., \& Assef, V. C. (2004). Control de la respuesta psicológica en el paciente quirúrgico pediátrico. MediCiego, 10(Supl.2). Recuperado de http://bvs.sld.cu/revistas/ mciego/vol10_supl2_04/revisiones/r8_v10_supl204.htm

Gimenes, B. P. (2008). O Brincar e a Saúde Mental. In D. Viegas, Brinquedoteca Hospitalar (p. 165). Rio de Janeiro, Brasil: Wak.

Gusman, D. P. P., Grecca, K. R. R., \& Magalhães, F. M. (2010). Preparo psicológico em pacientes submetidos a cirurgia cardíaca pediátrica. Revista Brasileira de Terapias Cognitivas, 6(2). Recuperado de http://pepsic.bvsalud.org/scielo. php?script=sci_arttext\&pid=S1808-56872010000200008

Jansen, M. F., Santos, R. M., \& Favero, L. (2010). Benefícios da utilização do brinquedo durante o cuidado de enfermagem prestado a criança hospitalizada. Revista Gaúcha de Enfermagem, 31(2); 247-53. Recuperado de http://www.scielo.br/pdf/rgenf/v31n2/07.pdf. doi: 10.1590/S1983-14472010000200007
Kovács, M. J. (2008). A Criança e a Morte. In D. Viegas, Biblioteca Hospitalar (p. 165). Rio de Janeiro: Wak.

Lemos, L. C. S., Oliveira, J. D., Gomes, E. B., Silva, K. V. L., Silva, P. K. S., \& Fernandes, G. P. (2016). Brinquedo Terapêutico no procedimento de punção venosa: estratégias para reduzir alterações comportamentais. Revista Cuidarte, 7(1), 116370. Recuperado de http://www.scielo.org.co/pdf/cuid/ v7n1/v7n1a04.pdf. doi: 10.15649/cuidarte.v7i1.303

Lobato, L., Gazzinelli, A., Pedroso, L. S., Barbosa, R., Santos, F. M. M., \& Gazzinelli, M. F. (2016). Conhecimento de crianças sobre o termo de assentimento livre e esclarecido. Revista Bioética, 24(3), 542-56. Recuperado de http://www.scielo. br/pdf/bioet/v24n3/1983-8042-bioet-24-03-0542.pdf. doi: $\underline{10.1590 / 1983-80422016243154}$

López, J. A. (2005). Programa de Preparación Psicológica en Cirugía Infantil Programada. Revista Profesional Española de Terapia Cognitivo-Conductual, 3, 56-70. Recuperado de http://files.sld.cu/anestesiologia/files/2012/08/programade-pre-preop-psicologica-ninos.pdf

Maia, E. B. S., Ribeiro, C. A., \& Borba, R. I. H. (2008). Brinquedo terapêutico: benefícios vivenciados por enfermeiras na prática assistencial a criança e família. Revista Gaúcha de Enfermagem, 29(1), 39-46. Recuperado de https:// seer.ufrgs.br/RevistaGauchadeEnfermagem/article/ view/5262/2996

Ministério da Educação e do Desporto (1988). Secretaria de Educação Fundamental. Referencial curricular nacional para a educação infantil. Brasília: Autor. Recuperado de http:// portal.mec.gov.br/seb/arquivos/pdf/rcnei_vol1.pdf

Ministério da Saúde (2013). HumanizaSUS: Método. Política Nacional de Humanização (PNH). Brasília: Autor: Recuperado de http://bvsms.saude.gov.br/bvs/ publicacoes/politica_nacional_humanizacao_pnh_folheto. pdf

Mitre, R. M. A., \& Gomes, R. (2004). A promoção do brincar no contexto da hospitalização infantil como ação de saúde. Ciência e Saúde Coletiva, 9(1), 147-154. Recuperado de http://www.scielo.br/pdf/csc/v9n1/19832.pdf. doi: 10.1590/S1413-81232004000100015

Nunes, C. J. R. R., Rabelo, H. D., Falcão, D. P., \& Picanço, M. R. A. (2013). A importância da brinquedoteca hospitalar e da terapia ocupacional sob a ótica da equipe de enfermagem de um hospital público do Distrito Federal. Cadernos Brasileiro de Terapia Ocupacional UFSCar, 21(3), 505-510. Recuperado de http://www. cadernosdeterapiaocupacional.ufscar.br/index.php/ cadernos/article/view/910. doi: 10.4322/cto.2013.052

Oliveira, V. B. (2008). O Lúdico na Realidade Hospitalar. In D. Viegas, Brinquedoteca Hospitalar (p. 165). Rio de Janeiro: Wak. 
Paladino, C. M., Carvalho, R., \& Almeida, F. A. (2014). Brinquedo terapêutico no preparo para a cirurgia: comportamentos de pré-escolares no período transoperatório. Revista da Escola de Enfermagem da USP, 48(3), 423-9. Recuperado de http://www.scielo.br/pdf/reeusp/v48n3/pt_00806234-reeusp-48-03-423.pdf. doi: 10.1590/50080$\underline{623420140000300006}$

Peixoto, E. A., \& Mazambani, A. (2008). Programa de Preparo Psicológico Pré-Operatório Infantil. Recuperado de http:// www.cesumar.br/curtas/psicologia2008/trabalhos/ PROGRAMA_DE_PREPARO_PSICOLOGICO_PREOPERATORIO_INFANTIL.pdf

Schmitz, S. M., Piccoli, M., \& Vieria, C. S. (2003). A criança hospitalizada, a cirurgia e o brinquedo terapêutico: uma reflexão para a enfermagem. Ciência, Cuidado e Saúde, 2(1), 67-73. Recuperado de http://www.periodicos.uem. br/ojs/index.php/CiencCuidSaude/article/view/5570. doi: 10.4025/cienccuidsaude.v2i1.5570

Silva, R. D. M., Austregésilo, S. C., Ithamar, L., \& Lima, L. S. (2017). Brinquedo terapêutico no preparo de crianças para procedimentos invasivos: revisão sistemática. Jornal de Pediatria, 93(1), 6-16. Recuperado de http://www.redalyc. org/pdf/3997/399749991003.pdf

Souza, M. T., Silva, M. D., \& Carvalho, R. (2010). Revisão integrativa: o que é e como fazer. Einstein, 8(1), 102-6. Recuperado de http://www.scielo.br/pdf/eins/v8n1/pt_1679-4508eins-8-1-0102. doi: 10.1590/s1679-45082010rw1134

Tesser, N. L., \& Prebianchi, H. B. (2014). Atenção psicológica aos pacientes cirúrgicos adultos e infantis nos períodos pré e pós operatório. Anais do Encontro de Iniciação em Desenvolvimento Tecnológico e Inovação, Campinas, SP, Brasil, 4.

Torquato, I. M., Collet, N. C., Dantas, M. S., Jonas, M. F., Trigueiro, J. S., \& Nogueira, M. F. (2013). Assistência Humanizada à Criança Hospitalizada: Percepção do Acompanhante. Revista de Enfermagem UFPE, 7(9), 5541-9. Recuperado de https://periodicos.ufpe.br/revistas/revistaenfermagem/ article/viewFile/13672/16561. doi: 10.5205/reuol.352929105-1-SM.0709201323 